\title{
Patterns of oestrogen and testosterone excretion during pregnancy in a gorilla (Gorilla gorilla)
}

\author{
B. Seaton* \\ Wellcome Institute of Comparative Physiology, Zoological Society of London, Regent's Park, \\ London NWI $4 R Y, U . K$.
}

\begin{abstract}
Summary. Oestrogen and testosterone concentrations in the urine were determined by radioimmunoassay. Total oestrogen concentrations rose from $25 \mathrm{ng} / \mathrm{mg}$ creatinine in the non-pregnant animal to a mean of about $2 \mu \mathrm{g} / \mathrm{mg}$ creatinine in the 50 days before term. There was a significant $(P<0.001)$ correlation between oestrogen and testosterone concentrations until 11 days before parturition.
\end{abstract}

\section{Introduction}

The recent successful pregnancy of the gorilla 'Lomie' in the collection of the Zoological Society of London has provided a rare opportunity to study the patterns of hormone excretion during pregnancy in this endangered species. Hopper, Tullner \& Grey (1968) studied oestrogen excretion in a pregnant gorilla and showed that oestradiol was the major urinary oestrogen.

The present study was undertaken as part of a project on the measurement of urinary hormones during the oestrous cycle and pregnancy in a wide variety of mammals in order to provide more objective criteria for the breeding of these species in captivity. The value of such measurements is their potential to provide information about the reproductive status of an animal which cannot be quickly or reliably obtained from direct observation. Two aspects were of particular interest in this study: (1) the use of urinary oestrogen assays as a method for the early detection of a fertile mating; (2) the possibility that in gorillas a rapid decline in oestrogen excretion during pregnancy is indicative of impending fetal death, as in man (see Greene \& Touchstone, 1963; Heys, Scott, Oakey \& Stitch, 1968; Brown \& Beischer, 1972; Rao, 1976). Because testosterone is known to compete with oestrogens for binding sites on steroid hormone-binding globulin in man and this interaction may play an important role in regulating the action of these hormones (Burke \& Anderson, 1972), measurement of urinary testosterone levels was included in the later part of the study although there is, as yet, no information about the presence of a steroid hormone-binding globulin in gorillas. Urinary progestagens were not determined because a suitable routine method was unavailable.

\section{Materials and Methods}

'Lomie', a western lowland gorilla (Gorilla gorilla gorilla) was about 12 years old at the time of conception. In June 1975 she was sent to Bristol Zoo for mating with an adult male gorilla, 'Samson'. Conception occurred during the period 2-5 November 1975. 'Lomie' was transferred back to London Zoo on 28 February 1976 and gave birth to a normal healthy female on 16 July 1976 (256-259 days). With few exceptions, 'Lomie' was on public display throughout gestation.

At Bristol Zoo and London Zoo specimens of urine were collected from the drain of 'Lomie's' enclosure at about the same time each day, shortly after urination. Although every precaution was taken to avoid contamination of the specimens, dilution of the urine by very small volumes of residual tap-water in the drain could not be prevented, neither could the occasional inclusion of small amounts of cage material or faeces, but the urine samples were never grossly contaminated. The samples were filtered through fibre-glass paper (Whatman, grade GFA) and stored at -20 or $-40^{\circ} \mathrm{C}$ until analysed.

\footnotetext{
* Present address: Cholera Research Laboratory, P.O. Box 128, Dacca-2, Bangladesh.
} 
Any steroid glucuronates present (which do not cross-react with the antisera of the assays) were hydrolysed by incubation at $37^{\circ} \mathrm{C}$ for $1 \mathrm{~h}$ with 8 i.u. $\beta$-glucuronidase "Pasteur" (from E. coli; A.P.I. Laboratories Ltd, Rayleigh, Essex)/ $\mu$ l urine (Crowley \& Rosser, 1973).

The hydrolysed urine samples were diluted with an appropriate volume (usually 1:100 for the oestrogen assay and $1: 10$ for the testosterone assay) of Tris-buffered saline $(0.05 \mathrm{M}$ Tris- $\mathrm{HCl}$ buffer, pH $8 \cdot 0$, containing $0 \cdot 1 \mathrm{M}-\mathrm{NaCl}$ and $0 \cdot 1 \%(\mathrm{w} / \mathrm{v})$ sodium azide) to bring the hormone concentration into the working range of the assay $(50-500 \mathrm{pg} /$ tube) and then analysed directly, without extraction or chromatography, for oestrogens and testosterone by using optimized radioimmunoassay systems (Seaton, Lusty \& Watson, 1976). The antisera (obtained from Miles-Yeda Ltd, Slough, U.K.) were raised in a goat to oestradiol-17 $\beta$-BSA for the oestrogen assay and in a rabbit to testosterone-7 $\alpha-B S A$ for the testosterone assay. The cross-reactivities, determined in buffer, with other steroids are given in Table 1. The $\left[1,2,6,7-(\mathrm{n})^{3} \mathrm{H}\right]$ oestradiol-17 $(\mathrm{sp}$. act. $91 \mathrm{Ci} / \mathrm{mmol})$ and $\left[2,4,6,7-(\mathrm{n})^{3} \mathrm{H}\right]$ testosterone (sp. act. $78 \mathrm{Ci} / \mathrm{mmol}$ ) were obtained from the Radiochemical Centre, Amersham, U.K., and tested for radiochemical purity by thin-layer chromatography before use.

Table 1. The $\%$ cross-reactivities of the antisera, tested in buffer but not in gorilla urine

\begin{tabular}{|c|c|c|c|c|}
\hline & \multicolumn{2}{|c|}{ Antiserum to oestradiol-17 $\beta-\mathrm{BSA}$} & \multicolumn{2}{|c|}{ Antiserum to testosterone- $7 \alpha-\mathrm{BSA}$} \\
\hline & Experimental* & Manufacturer & Experimental* & Manufacturer \\
\hline Oestrone & 65 & 100 & - & - \\
\hline Oestradiol & $(100)$ & $(100)$ & $0 \cdot 015$ & $0 \cdot 1$ \\
\hline Oestriol & 34 & 15 & - & - \\
\hline Testosterone & - & $0-2$ & $(100)$ & $(100)$ \\
\hline Androsterone & - & - & $0+$ & - \\
\hline Dehydroepiandrosterone & - & - & 0.001 & 0.5 \\
\hline $5 \alpha$-Dihydrotestosterone & - & - & - & 42 \\
\hline 17 $\alpha$-Epitestosterone & - & - & - & 1 \\
\hline Progesterone & 0.05 & - & $0 \cdot 1$ & - \\
\hline Pregnanediol & 0.005 & - & $0+$ & - \\
\hline
\end{tabular}

* Determined under normal assay conditions.

$\dagger$ No detectable cross-reactivity in the presence of a concentration of hormone approximately equal to twice the upper range of normal in near-term human pregnancy urine.

The urine sample $(100 \mu \mathrm{l})$, labelled steroid $(200 \mu \mathrm{l}, \bumpeq 50 \mathrm{pg})$ and antiserum $(200 \mu \mathrm{l})$ were incubated together at $4^{\circ} \mathrm{C}$ overnight; the free steroid was removed by the addition of $200 \mu \mathrm{l}$ charcoal/dextran and $500 \mu \mathrm{l}$ of the supernatant were removed for determination of the bound labelled steroid by liquid scintillation counting. For hormone concentrations near the assay optima (see Seaton et al., 1976) typical intra- and interassay coefficients of variation were 1.4 and $3.0 \%$ respectively for the testosterone assay and $2 \cdot 0$ and $3.5 \%$ for the oestrogen assay. Blanks were never appreciably different from zero.

As 24-h urine collections were impossible, a correction for variations in urine volumes was made by relating the hormone levels to the urinary creatinine concentration determined colorimetrically (Slott, 1965). The applicability of the assay method was checked by measurement of oestrogen and testosterone in early morning (i.e. first-voided) human urine samples obtained from normal healthy volunteers.

\section{Results}

The urinary creatinine, oestrogens and testosterone concentrations during the pregnancy of the gorilla are illustrated in Text-fig. 1. The observed oestrogen values are considered as representing the overall trend rather than the absolute concentrations because oestrone, oestradiol and oestriol have different cross-reactions with the antiserum used. 

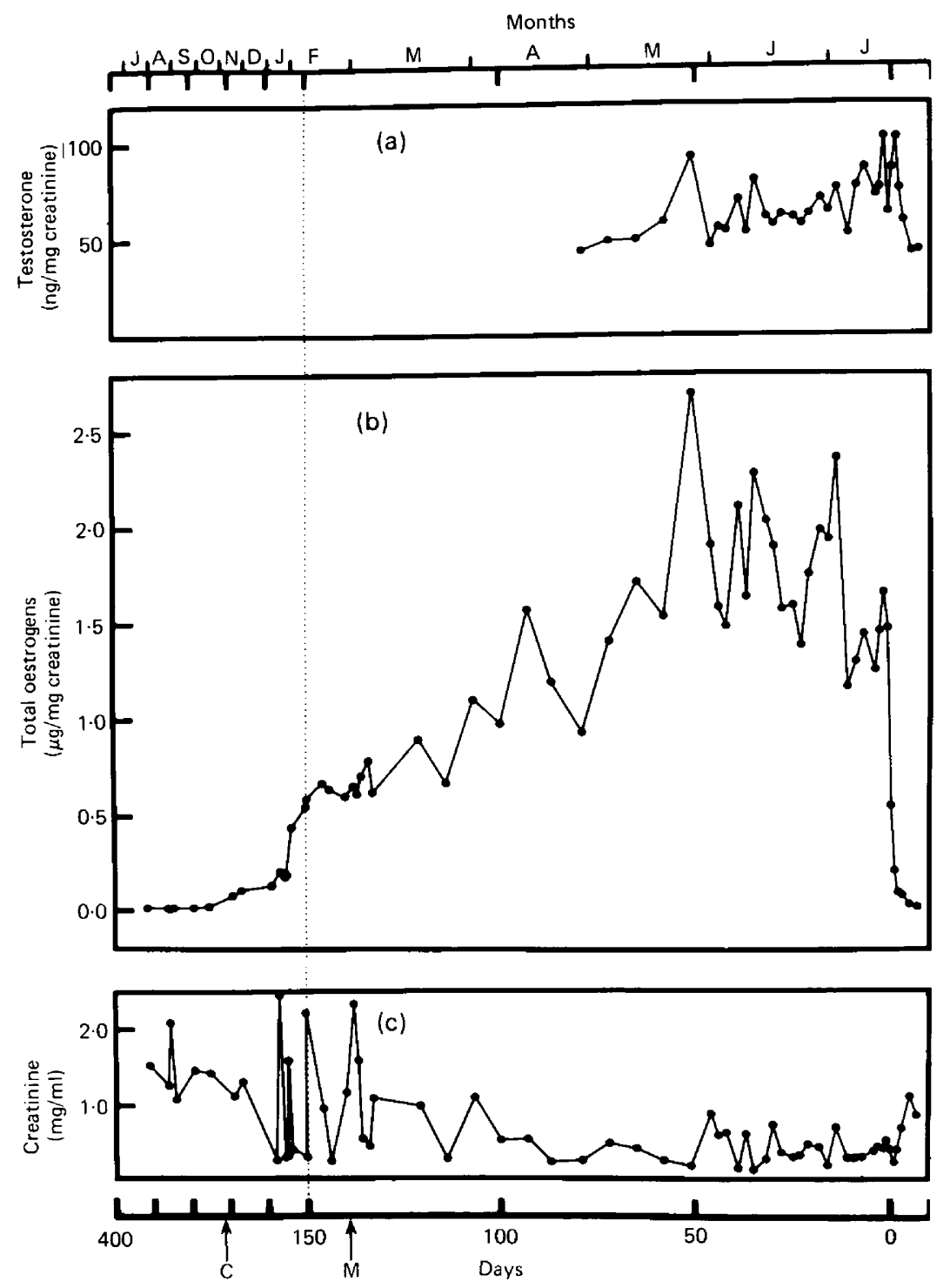

Text-fig. 1. The patterns of urinary concentrations of (a) testosterone, (b) total oestrogens and (c) creatinine before, during and after pregnancy in the gorilla 'Lomie'. Day $0=$ parturition; $C=$ conception; $M=$ move back to London. Note the change in the time scale at Day 150.

The hormone concentrations in the human urine samples are given in Table 2; they are comparable to those obtained by Ismail \& Harkness (1966) and Brown \& Beischer (1972: see Text-fig. 2).

The urinary testosterone levels during the last 10 weeks of pregnancy in the gorilla (Text-fig. 1) were as high as those in adult human males (Table 2). The post-partum decline was less rapid than that of oestrogen excretion. Although urinary excretion of testosterone did not fluctuate to the same degree as that of oestrogens, there was a highly significant $(P<0.001)$ correlation between the oestrogen and testosterone levels from 79 to 11 days before parturition, but this changed dramatically during the last 9 days of pregnancy (Text-fig. 3). 


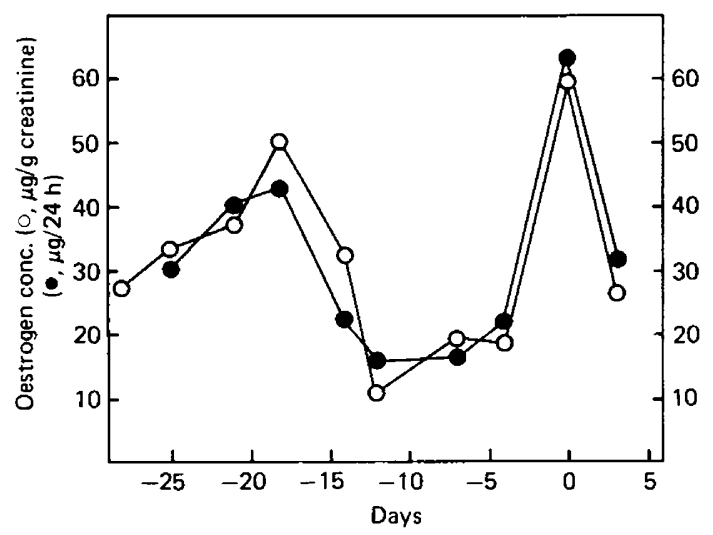

Text-fig. 2. A comparison of oestrogen concentrations in the urine of cyclic non-pregnant women determined by the radioimmunoassay described in this paper for the gorilla $(0)$ and those given by Brown \& Beischer (1972) from a spectrofiuorometric assay (๑). Day 0 is the day of the oestrogen peak.

Table 2. A comparison of the mean concentrations in gorilla and human urine of the oestrogens and testosterone measured by the radioimmunoassay described

\begin{tabular}{llcc}
\hline Species & Reproductive status & $\begin{array}{c}\text { Oestrogen } \\
\text { (ng/mg creatinine) }\end{array}$ & $\begin{array}{c}\text { Testosterone } \\
\text { (ng/mg creatinine) }\end{array}$ \\
\hline Gorilla & Non-pregnant & 25 & - \\
Man & Pregnant, near-term & 2000 & 75 \\
Female & Non-pregnant, mid-cycle & & 20 \\
& Non-pregnant, menstruating & 60 & 10 \\
& Pregnant, 2nd trimester & 10 & $30-70$ \\
Male & Immature girl (8 years) & $200-1000$ & 10 \\
& & 7 & $70-130$ \\
\hline
\end{tabular}



Text-fig. 3. Demonstration of the correlation between oestrogen and testosterone concentration in gorilla urine from 79 to 11 days before parturition (๑), from 9 to 1 day before birth $(0)$, and after birth $(\diamond)$. The day of collection is indicated by the number against the open symbols. The regression line $(-)$ was calculatde by the reduced major axis procedure (Kermack \& Haldane, 1950) which allows for errors of the same magnitude in both co-ordinates. The stippled area represents \pm 2 standard deviations from the regression line for which testosterone conc. $=0.029$ (oestrogen conc.) $+8 \cdot 5$. 


\section{Discussion}

The overall values for oestrogen in the urine of the gorilla are similar to those obtained by Hopper $e t$ al. (1968) who used a gas-liquid chromatographic method. This, together with the correspondence of the measurements in human urine, suggests that the methods used in the present study are capable of producing meaningful data on patterns of hormone excretion.

The procedure for correcting hormone concentrations on the basis of creatinine concentrations also appears to be valid for the gorilla in that when there were two or more urine samples separated by relatively short intervals (e.g. 1 day) the corrected hormone levels were similar, even though the absolute hormone concentrations and the urine volume (as judged by the creatinine concentration) may have been quite different.

Although the major urinary oestrogen in women is oestriol, not oestradiol as in the gorilla (Hopper et al., 1968), the excretion pattern in the two species is similar. As in women (Brown \& Beischer, 1972), urinary total oestrogen excretion by the gorilla rises throughout pregnancy, the nearterm levels being some three orders of magnitude greater than those in the non-pregnant animal. The data show that it is practicable to monitor oestrogen excretion routinely in the gorilla to provide an early diagnosis of pregnancy (steadily rising oestrogen levels).

In the gorilla, as in women (Smith, 1966; De Hertogh, Thomas, Bietlot, Vanderheyden \& Ferin, 1975), chimpanzees (Reyes, Winter, Faiman \& Hobson, 1975) and rhesus monkeys (Bosu, Johansson \& Gemzell, 1973), considerable fluctuations in the levels of oestrogen were observed. The data obtained during the more frequent sampling in late pregnancy suggest that the fluctuations are regular rather than random (see Text-fig. 1). The occurrence of periodic phenomena during pregnancy has been observed previously (Swezy \& Evans, 1930; Richards, 1964). The loss of correlation between oestrogen and testosterone levels just before parturition has not been reported for other species. However, a similar pre-partum change in oestrogen-testosterone ratios may occur in women because Mizuno, Lobotsky, Lloyd, Kobayaski \& Murasawa (1968) found a pre-partum rise in plasma testosterone and Smith (1966) describes a pre-partum decline in plasma oestrogen levels, although Turnbull et al. (1974) recorded a rise in plasma oestradiol levels at this time. Therefore, the potential value of oestrogen-testosterone ratios, rather than oestrogen levels alone, in pregnancy monitoring remains to be determined.

I thank the menagerie staff at Bristol and London Zoos for collecting urine samples under difficult conditions and colleagues for their advice and encouragement. The work was supported by grants from the Ford Foundation and the Medical Research Council.

\section{References}

Bosu, W.T.K., Johansson, E.D.B. \& Gemzell, C.G. (1973) Peripheral plasma levels of oestrogens, progesterone and 17 $\alpha$-hydroxyprogesterone during gestation in the rhesus monkey. Acta endocr., Copenh. 74, 348-360.

Brown, J.B. \& Beischer, N.A. (1972) Current status of oestrogen assay in gynaecology and obstetrics. Obstetl gynec. Surv. 27, 205-235.

Burke, C.W. \& Anderson, D.C. (1972) Sex-hormonebinding globulin is an oestrogen amplifier. Nature, Lond. 240, 38-40.

Crowley, M.F. \& Rosser, A. (1973) Oestrogen determination in pregnancy urine using enzymatic hydrolysis of oestrogen conjugates. Clin. chim. Acta 49, 115-122.
De Hertogh, R., Thomas, K., Bietlot, Y., VanderHEYDEN, I. \& FERIN, J. (1975) Plasma levels of unconjugated oestrone, oestradiol and oestriol and of HCS throughout pregnancy in normal women.J. clin. Endocr. Metab. 40, 93-101.

Greene, J.W. \& Touchstone, J.C. (1963) Urinary oestriol as an index of placental function. Am. J. Obstet. Gynec. 85, 1-9.

Heys, R.F., Scott, J.S., OAKey, R.E. \& Stitch, S.R. (1958) Urinary oestrogen in late pregnancy. Lancet $\mathbf{i}$, 328-330.

Hopper, B.R., Tullner, W.W. \& Grey, C.W. (1968) Urinary oestrogen excretion during pregnancy in a gorilla. Proc. Soc. exp. Biol. Med. 129, 213-214. 
Ismail, A.A.A. \& Harkness, R.A. (1966) A method for the estimation of urinary testosterone. Biochem.J.99, 717-725.

Kermack, K.A. \& Haldane, J.B.S. (1950) Organic correlation and allometry. Biometrika 37, 30-41.

Mizuno, M., LobotSky, J., Lloyd, C.W., Kobayashi, T. \& Murasawa, Y. (1968) Plasma androstenedione and testosterone during pregnancy and in the newborn. J. clin. Endocr. Metab. 28, 1133-1142.

RAO, L.G.S. (1976) Clinical usefulness of oestrogencreatinine ratios in random samples of urine as a foeto-placental function test. $J$. Endocr. 68, 40P-41P.

Reyes, F.I., Winter, J.S.D., Faiman, C. \& Hobson, W.C. (1975) Serial serum levels of gonadotropins, prolactin and sex steroids in the nonpregnant and pregnant chimpanzee. Endocrinology 96, 1447-1455.

RichARDS, M.P.M. (1964) Cyclical behavioural activity in the pregnant golden hamster (Mesocricetus auratus Waterhouse). Nature, Lond. 204, 1327-1328.
Seaton, B., Lusty, J.A. \& Watson, J. (1976) A practical model for steroid hormone radioimmunosasays. $J$. Steroid Biochem. 7, 511-516.

SLorr, C. (1965) Plasma creatinine determination. A new and specific Jaffe reaction method. Scand. J. clin. Lab. Invest. 17, 381-387.

Smith, O.W. (1966) Free and conjugated oestrogens in blood and urine before and during parturition in normal human pregnancy. Acta endocr., Copenh., Suppl. 104, 1-31.

Swezy, O. \& Evans, H.M. (1930) Ovarian changes during pregnancy in the rat. Science, $N . Y .71,46$.

Turnbull, A.C., Flint, A.P.F., Jeremy, J.Y., Patten, P.T., KeIRSE, M.J.N.C. \& ANDERSON, A.B.M. (1974) Significant fall in progesterone and rise in oestradiol levels in human peripheral plasma before onset of labour. Lancet i, 101-104.

Received 30 August 1977 